\title{
Effects of Ni implantation into bulk and epitaxial GaP on structural and magnetic characteristics
}

\author{
M.E. Overberg ${ }^{\mathrm{a}, *}$, N. Theodoropoulou ${ }^{\mathrm{b}}$, S.N.G. Chu ${ }^{\mathrm{c}}$, S.J. Pearton ${ }^{\mathrm{a}}$, \\ C.R. Abernathy ${ }^{a}$, A.F. Hebard ${ }^{\text {b }}$, R.G. Wilson ${ }^{\mathrm{d}}$, J.M. Zavada ${ }^{\mathrm{e}}$ \\ ${ }^{a}$ Department of Materials Science and Engineering, University of Florida, Gainesville, FL 32611, USA \\ ${ }^{\mathrm{b}}$ Department of Physics, University of Florida, Gainesville, FL 32611, USA \\ ${ }^{\mathrm{c}}$ Agere Systems, Murray Hill, NJ 07974, USA \\ ${ }^{\mathrm{d}}$ Stevenson Ranch, CA 91381, USA \\ e Army Research Office, Research Triangle Park, NC 27709, USA
}

Received 4 December 2001; accepted 11 December 2001

\begin{abstract}
Structural and magnetic characteristics of Ni-implanted GaP were measured for doses in the range $3-5 \times 10^{16} \mathrm{~cm}^{-2}$. After subsequent annealing at $700{ }^{\circ} \mathrm{C}$, transmission electron microscopy (TEM) showed residual lattice damage which was more significant in highly carbon-doped epi layers as compared to bulk GaP substrates. The magnetization measurements showed two different contributions, one present at $\leq 75 \mathrm{~K}$ and the other below $\sim 225 \mathrm{~K}$. No secondary phase formation was detected in either type of GaP. (C) 2002 Elsevier Science B.V. All rights reserved.
\end{abstract}

Keywords: Ni implantation; Charge carriers; Semiconductors

\section{Introduction}

The possibility of exploiting spins of charge carriers in semiconductors in addition to their charge has raised interest in combining magnetic, electronic and optical functionalities onto a single chip [1-7]. While spinselective transport is employed in magnetic memories and field sensors, the production of practical dilute magnetic semiconductors has proven elusive [8]. In Mndoped GaAs and InAs for example, the transition temperatures are very low $(<105 \mathrm{~K})$. Since the Curie temperature is predicted to be a strong function of bandgap, magnetic ion concentration and carrier concentration in the semiconductor, it has been proposed that materials with gaps much larger than GaAs and InAs should be investigated [9]. There has been some success in initial experiments on $(\mathrm{Ga}, \mathrm{Mn}) \mathrm{N}$, prepared either by bulk growth processes $[10,11]$ or direct

\footnotetext{
* Corresponding author.
}

implantation of $\mathrm{Mn}$ into $\mathrm{GaN}[12,13]$. The bulk crystals exhibit paramagnetic behavior, while the implanted $\mathrm{GaN}$ shows ferromagnetic contributions to the magnetism below $\sim 250 \mathrm{~K}$.

$\mathrm{GaP}$ has a large bandgap $(2.2 \mathrm{eV})$ and is an important component of the AlGaInP materials system, which is used for visible light-emitting diodes and high-speed electronics. To date, there have been few reports on the incorporation of magnetic ions into GaP. Epitaxial films of $(\mathrm{Ga}, \mathrm{Mn}) \mathrm{P}$ have shown single-phase material up to Mn atomic concentrations of $\sim 7 \%$, but with low Curie temperatutes [14].

In this paper we report on the effects of high dose $\mathrm{Ni}$ implantation into nominally undoped n-type bulk GaP wafers and heavily C-doped p-type $\mathrm{GaP}$ epitaxial layers. This study enabled the comparison between the magnetic properties in the presence of either electrons or holes. This is important for determining the origin of ferromagnetism in dilute magnetic semiconductors since it is carrier-mediated and may work only with p-type material [9]. Our results show two contributions to the 


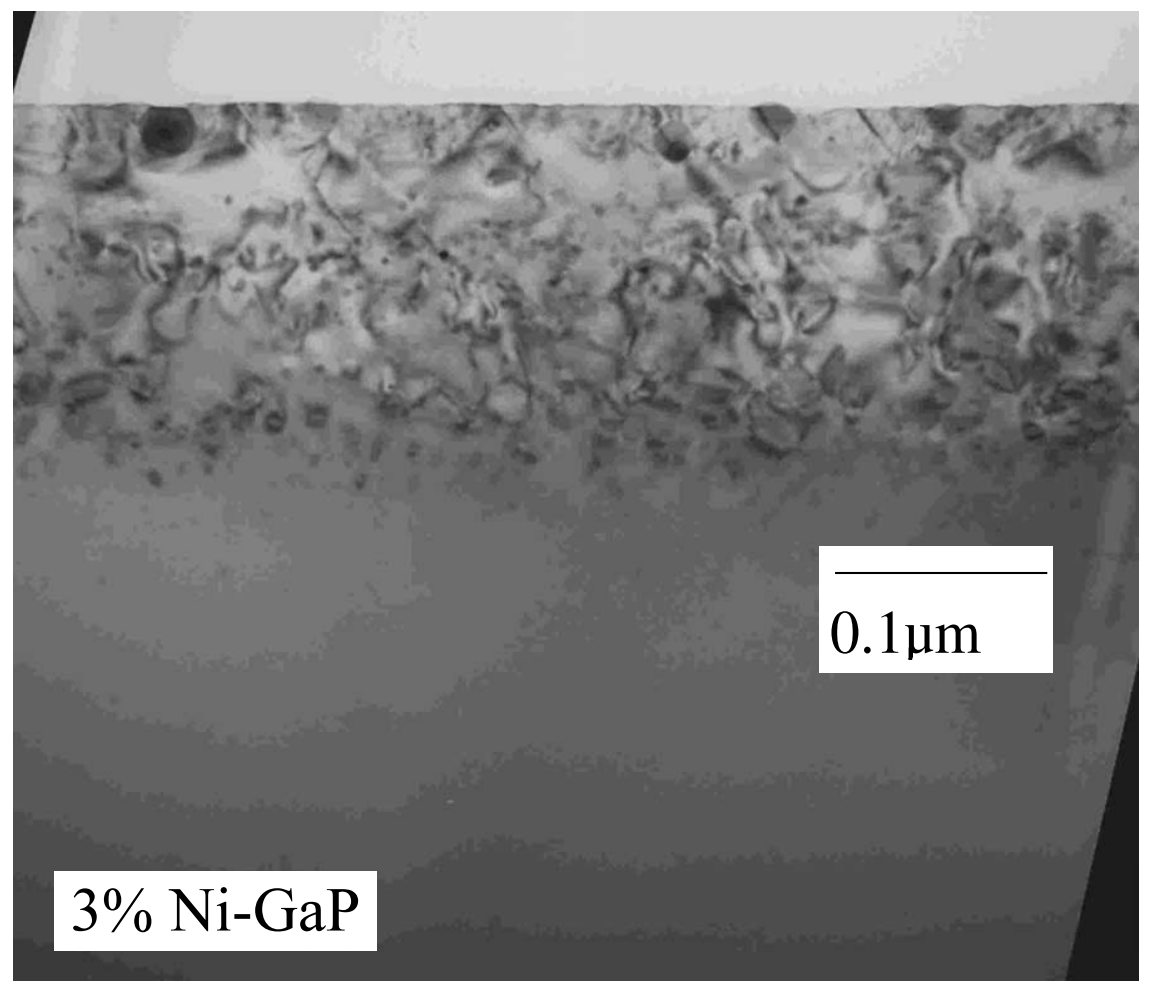

Fig. 1. TEM cross-section from bulk GaP implanted with $3 \times 10^{16} \mathrm{~cm}^{-2} \mathrm{Ni}^{+}$ions and annealed at $700{ }^{\circ} \mathrm{C}$.

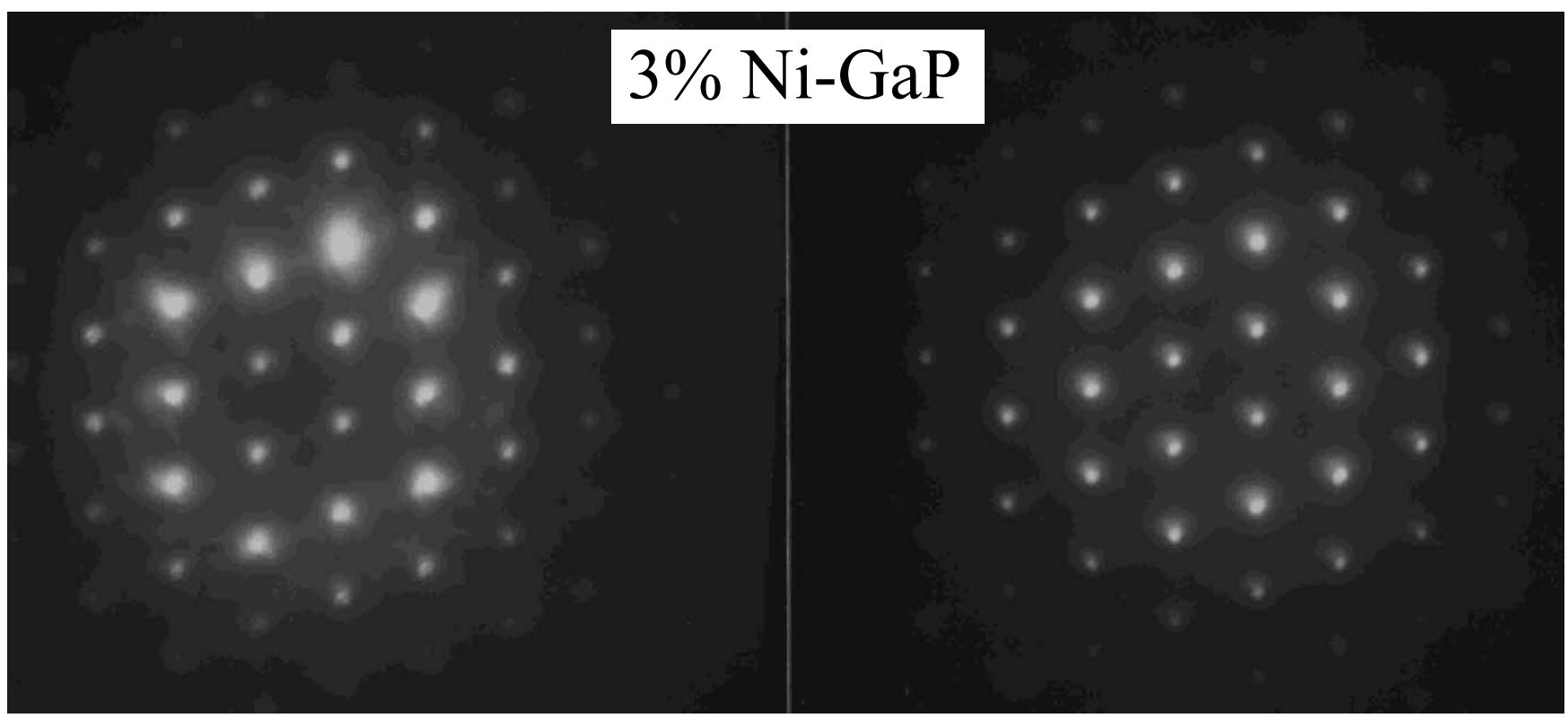

Fig. 2. Selected area diffraction pattern from bulk GaP implanted with $3 \times 10^{16} \mathrm{~cm}^{-2} \mathrm{Ni}^{+}$ions and annealed at $700{ }^{\circ} \mathrm{C}$.

ferromagnetism in both types of Ni-implanted $\mathrm{GaP}$, one which is present below $\sim 75 \mathrm{~K}$ and the other which remains until $\sim 225 \mathrm{~K}$. No evidence of secondary phase formation was found by selected area diffraction pattern analysis or by transmission electron microscopy (TEM).

\section{Experimental}

Two types of GaP were used in these experiments. The first were bulk (100) substrates that were nominally undoped n-type with $10^{16} \mathrm{~cm}^{-3}$ background carrier densities. The second type were $0.4 \mu \mathrm{m}$ thick epi layers 
Table 1

Potential second phases that could form in Ni-implanted GaP

\begin{tabular}{llclc}
\hline $\begin{array}{l}\text { GaNiP } \\
\text { Phase }\end{array}$ & Structure & a & b & c \\
\hline $\mathrm{Ni}$ & Cubic & 3.5238 & & \\
$\mathrm{Ni}$ & Hexagonal & 2.6515 & & 4.343 \\
$\mathrm{NiP}$ & Orthorhombic & 6.050 & 4.881 & 6.891 \\
$\mathrm{NiP}_{2}$ & Cubic & 5.4706 & & \\
$\mathrm{NiP}_{2}$ & Monoclinic & 6.366 & 5.615 & 60.72 \\
$\mathrm{Ni}_{2} \mathrm{P}$ & Hexagonal & 5.86 & & 3.37 \\
$\mathrm{Ni}_{2.55} \mathrm{P}$ & Hexagonal & 13.22 & & 24.634 \\
$\mathrm{Ni}_{3} \mathrm{P}$ & Tetragonal & 8.952 & & 4.388 \\
$\mathrm{Ni}_{5} \mathrm{P}_{2}$ & Hexagonal & 13.220 & & 24.632 \\
$\mathrm{Ni}_{5} \mathrm{P}_{4}$ & Hexagonal & 6.789 & & 10.986 \\
$\mathrm{Ni}_{7} \mathrm{P}_{3}$ & Cubic & 8.64 & & \\
$\mathrm{Ni}_{12} \mathrm{P}_{5}$ & Tetragonal & 8.646 & & 5.071 \\
\hline
\end{tabular}

grown by metal organic molecular beam epitaxy on top of $\mathrm{GaP}$ substrates. These layers were heavily C-doped $\left(p \sim 10^{20} \mathrm{~cm}^{-3}\right.$ ) using carbon tetrabromide as the dopant source.

The samples were implanted with $250 \mathrm{keV} \mathrm{Ni}^{+}$ions to doses of $3-5 \times 10^{16} \mathrm{~cm}^{-2}$ at a temperature of $350{ }^{\circ} \mathrm{C}$ in order to avoid amorphization. These conditions produced maximum $\mathrm{Ni}$ concentrations of $2-3 \times$ $10^{16} \mathrm{~cm}^{-3}$ at the projected range of $\sim 0.2 \mu \mathrm{m}$ deep in each sample. After implantation, annealing was performed at $700{ }^{\circ} \mathrm{C}$ under a flowing $\mathrm{N}_{2}$ ambient. The samples were characterized by TEM, selected area diffraction pattern (SADP) analysis, SQUID magnetometry and double crystal X-ray diffraction (DC-XRD).

\section{Results and discussion}

Fig. 1 shows a cross-sectional TEM micrograph from a bulk GaP crystal implanted with $3 \times 10^{16} \mathrm{~cm}^{-2} \mathrm{Ni}^{+}$ ions and then annealed. The damaged region extends $\sim$ $0.42 \mu \mathrm{m}$ from the surface, but remains single-crystal. This microstructure is typical of compound semiconductors implanted with high ion doses $[15,16]$, in which a variety of lattice defects are created and are relatively stable against annealing. It is well established that extended defects have only a second-order effect on the electrical properties of implanted layers in compound semiconductors [15].

The SADPs from the damaged (left) and control (right) samples are shown in Fig. 2. The diffraction patterns are similar and indicate (at least to the resolution of the technique) that no secondary phases are formed by the $\mathrm{Ni}^{+}$implantation. Table 1 shows a listing of potential other compounds that could conceivably form with high doses of $\mathrm{Ni}^{+}$into GaP. Only $\mathrm{Ni}_{7} \mathrm{P}_{3}$ and cubic $\mathrm{NiP}_{2}$ have the same lattice symmetry as the host $\mathrm{GaP}$, and both would give rise to additional
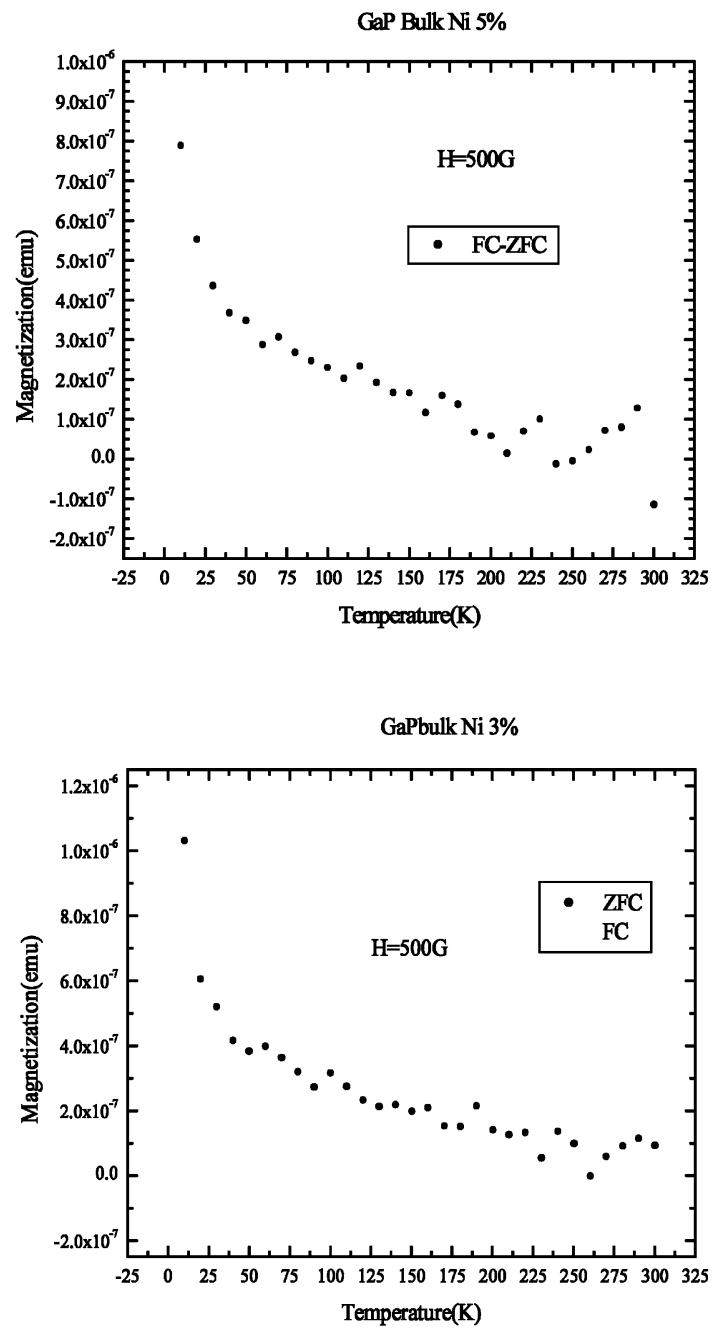

Fig. 3. Temperature dependence of difference between field-cooled and zero filed-cooled magnetization from bulk GaP implanted with either $5 \times 10^{16} \mathrm{~cm}^{-2}$ (top) or $3 \times 10^{16} \mathrm{~cm}^{-2}$ (bottom) $\mathrm{Ni}^{+}$ions and annealed at $700{ }^{\circ} \mathrm{C}$.

spots in the diffraction pattern from the implanted region.

Fig. 3 shows the temperature dependence of the difference in magnetization signal under field-cooled and zero field-cooled conditions for bulk GaP samples implanted with either $5 \times 10^{16} \mathrm{~cm}^{-2}$ (top) or $3 \times 10^{16}$ $\mathrm{cm}^{-2}$ (bottom) $\mathrm{Ni}^{+}$and annealed at $700{ }^{\circ} \mathrm{C}$. The data show two contributions to the magnetization (large diamagnetic and paramagnetic backgrounds have been subtracted), with one present at $\leq 75 \mathrm{~K}$ and the other extending out to $\sim 200-225 \mathrm{~K}$ depending on the implant dose. The low temperature transition is also seen in of the results for $\mathrm{GaN}(\mathrm{Fe})$ created by epitaxial growth or direct implantation of $\mathrm{Fe}$ into $\mathrm{GaN}$ epi layers and for $\mathrm{GaN}$ and $\mathrm{SiC}$ implanted with Ni. As evidence of ferromagnetic behavior, the Ni-implanted GaP showed a hysteresis in the magnetic moment for both doses, with a coercivity of $\sim 200$ Oe at $10 \mathrm{~K}$. We have also observed 
I

\section{3\%Ni-GaPepi}

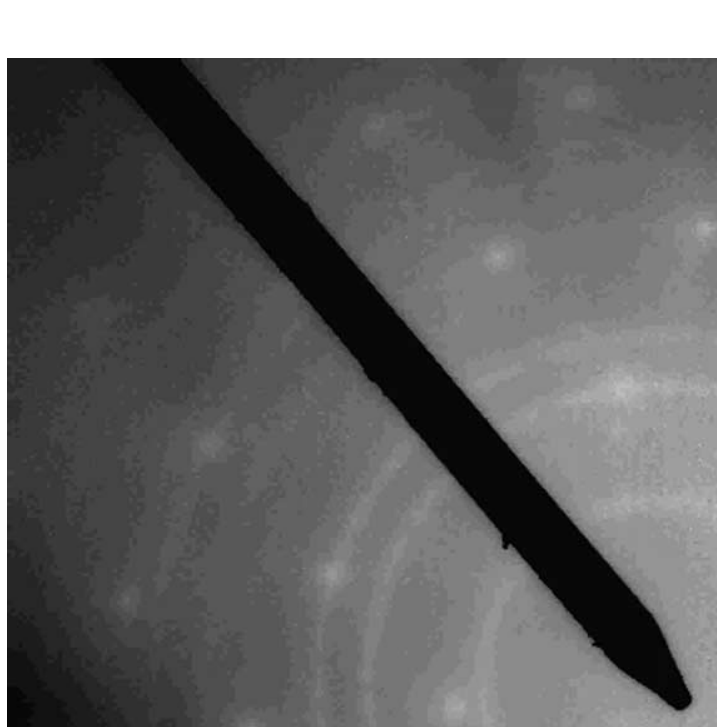

$0.1 \mu \mathrm{m}$

\section{3\%Ni-GaPepi}

Fig. 4. TEM cross-section (top) and SADP (bottom) from epi GaP implanted with $3 \times 10^{16} \mathrm{~cm}^{-2} \mathrm{Ni}^{+}$ions and annealed at 700 

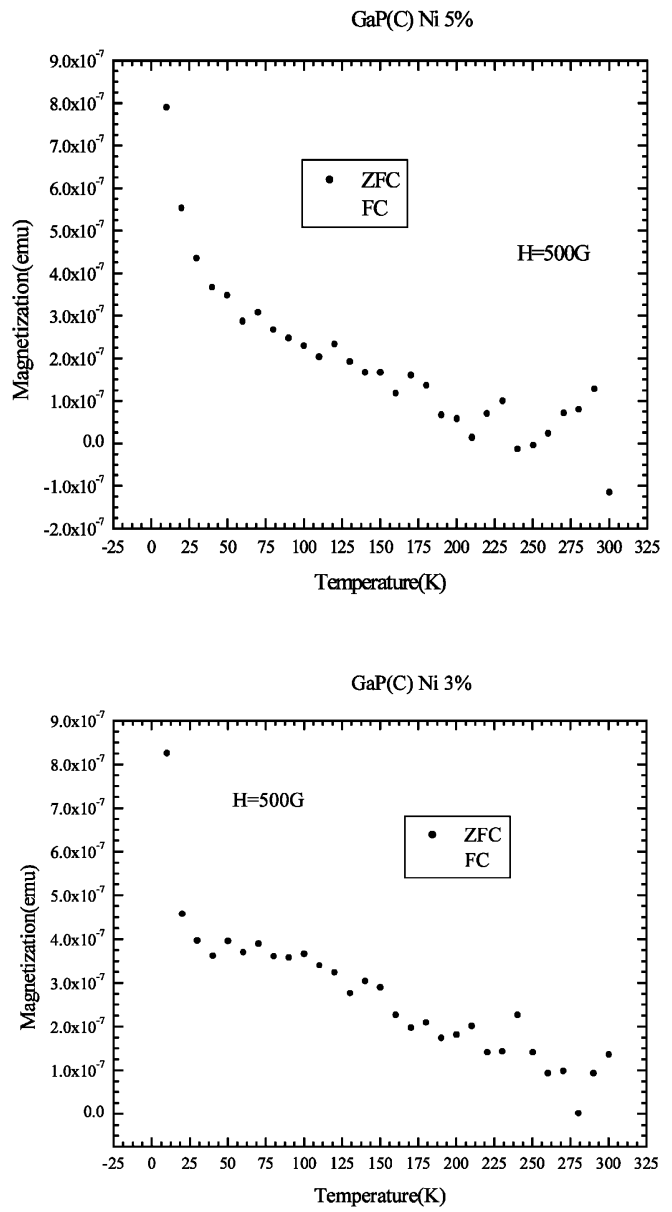

Fig. 5. Temperature dependence of difference between field-cooled and zero field-cooled magnetization from epi GaP implanted with either $5 \times 10^{16} \mathrm{~cm}^{-2}$ (top) or $3 \times 10^{16} \mathrm{~cm}^{-2}$ (bottom) $\mathrm{Ni}^{+}$ions and annealed at $700{ }^{\circ} \mathrm{C}$.

similar high temperature $(100-250 \mathrm{~K})$ magnetization in $\mathrm{Mn}$ - and Fe-implanted $\mathrm{GaN}$ and Fe-implanted $\mathrm{SiC}$ previously [12-14]. The formation of $\mathrm{GaNi}_{x} \mathrm{P}_{1-x}$ was not confirmed in our samples, and we are currently examining the material by z-contrast electron microscopy to establish the distribution of $\mathrm{Ni}$ in the implanted region.

Fig. 4 shows a TEM cross-sectional micrograph (top) from the epi GaP implanted with $3 \times 10^{16} \mathrm{~cm}^{-2} \mathrm{Ni}^{+}$ ions and annealed at $700{ }^{\circ} \mathrm{C}$, along with its associated SADP (bottom) from the implanted region. The epi layer has more residual damage than its bulk counterpart processed under the same conditions, suggesting that the high level of carbon doping stabilizes the lattice disorder somewhat against annealing. This may be due to the migration of carbon atoms to dislocations and loops. The SADP shows only rings that seem to originate from poly $\mathrm{GaP}$ in an amorphous matrix that did not completely regrow during the implant and anneal cycle. Note however that no secondary phases were present in the epi-implanted material.
Fig. 5 shows the SQUID data from the implanted epitaxial GaP samples for both the $5 \times 10^{16} \mathrm{~cm}^{-2}$ dose (top) and the $3 \times 10^{16} \mathrm{~cm}^{-2}$ dose (bottom). The temperature dependence of the field-cooled minus zero field-cooled magnetization showed two ferromagnetic contributions, as did the bulk samples. The transition temperatures are roughly the same in both types of material, suggesting that the carrier concentration difference (in both level and conductivity type) is not a significant factor in the magnetization. The coercivity obtained from the hysteresis curve at $10 \mathrm{~K}$ was $\sim 150$ Oe. Similar results were reported for Fe-doped $\mathrm{GaN}$ grown by molecular beam epitaxy [4]. At this stage, there is no clear explanation for the origin of the magnetic behavior in these wide bandgap semiconductors doped with magnetic elements. Further clarification is needed on the role of superparamagnetic clusters or spin-glass behavior in these materials. In the case of the Fe-doped GaN [4], Extended X-ray absorption fine structure and high resolution TEM suggested that $\mathrm{Fe}$ atoms in single-phase material were occupying $\mathrm{Ga}$ sites with no evidence of precipitation. In this material the carrier concentration was also too low to expect carrierinduced ferromagnetism [4].

\section{Summary and conclusions}

$\mathrm{GaP}(\mathrm{Ni})$ created by implantation into epi or bulk $\mathrm{GaP}$ showed ferromagnetic behavior. The origin of the magnetism is not clear, but is similar to that reported in other wide bandgap semiconductors doped with magnetic elements. Since the Curie temperature for carrierinduced ferromagnetism is proportional to the carrier density in the material, it is likely that implantation is not the best approach since residual damage may lead to trapping of the electrons or holes. However, it is an effective method for rapid screening of the magnetic properties of different elements in $\mathrm{GaP}$ and other semiconductors of potential interest for spin-polarized applications.

\section{Acknowledgements}

The work at UF is partially supported by NSF (SMR 0101438) while that of RGW is partially supported by ARO.The authors are grateful to Professor S. Mahajan (ASU) for helpful comments.

\section{References}

[1] H. Ohno, D. Chibu, F. Matsukura, T. Omiya, E. Abe, T. Dietl, Y. Ohno, K. Ohtani, Nature 408 (2000) 944. 
[2] A. Van Esch, L. Bockstal, J. de Boeck, G. Verbank, A. Van Steenbergen, B. Grietens, R. Bogaerts, F. Herlach, G. Borghs, Phys. Rev. B56 (1997) 13103.

[3] T. Dietl, A. Haury, Y.M. Aubigne, Phys. Rev. B55 (1997) R3347.

[4] H. Akinaga, S. Nemeth, J. de Boeck, L. Nistor, H. Berdes, G. Borghs, H. Ofuchi, M. Oshima, Appl. Phys. Lett. 77 (2000) 4377.

[5] T. Hayashi, M. Tanaka, T. Nishinaga, H. Shimada, J. Appl. Phys. 81 (1997) 4865.

[6] J. Shi, J.M. Kikkawa, R. Proksch, T. Schaffer, D.D. Awschalom, G. Medelos-Riberio, P.M. Petroff, Nature 377 (1995) 707.

[7] C. Chen, M. Cai, X. Wang, S. Wu, M. Zhang, X. Ding, Y. Sun, J. Appl. Phys. 87 (2000) 5636.

[8] G.A. Prinz, Science 282 (1998) 1660.

[9] T. Dietl, H. Ohno, F. Matsukura, J. Cibert, D. Ferrand, Science 287 (2000) 1010.

[10] W. Gebicki, J. Strzeszewski, G. Kamber, T. Szyszko, S. Podliado, Appl. Phys. Lett. 76 (2000) 3870.
[11] M. Zajac, R. Doradzinski, J. Gosk, T. Szczyko, M. Palezewski, G. Grazanaka, M. Lefeld-Sosnowska, W. Gebicki, M. Kaminska, T. Twardowski, Appl. Phys. Lett. 78 (2001) 1276.

[12] N. Theodoropoulou, K.P. Lee, M.E. Overberg, C.R. Abernathy, S.J. Pearton, S.N.G. Chu, R.G. Wilson, Appl. Phys. Lett. 78 (2001) 3475.

[13] N. Theodoropoulou, K.P. Lee, M.E. Overberg, S.N.G. Chu, A.F. Hebard, C.R. Abernathy, S.J. Pearton, R.G. Wilson, J. Nanoscience Nanotech. 1 (2001) 101.

[14] M.E. Overberg, C.R. Abernathy, S.J. Pearton, F. Sharifi, A.F. Hebard, N. Theodoropoulou, S. von Molnar, M. Anane, P. Xiong, Presented at MRS Spring 2001 Meeting, San Francisco, April 2001, paper T6.5.

[15] S.J. Pearton, Int. J. Mod. Phys. B7 (1993) 4687

[16] S.O. Kucheyev, J.S. Williams, S.J. Pearton, Mater. Sci. Eng. R33 (2001) 51 . 